\title{
Development of the Attitude Scale Towards Crisis and Chaos Management in Education
}

\author{
Hatice Bilgin ${ }^{1 *}$, Behcet Öznacar ${ }^{1}$ \\ ${ }^{1}$ Near East University, Ataturk Faculty of Education, Nicosia, N. CYPRUS
}

Received 11 September 2017 - Revised 1 October 2017 • Accepted 15 October 2017

\begin{abstract}
This study was carried out with the aim of developing the Attitude Scale towards Crisis and Chaos Management of Higher Education Administrators. Firstly, literature search was carried out in the development process of the scale. Then, 10 open-ended questions were asked to 10 Higher Education administrators about crisis and chaos management. By using the obtained data and expert opinions, a 58-point item pool was created. Expert opinions were consulted to ensure content validity. Corrections were made in line with the opinions and recommendations of the experts. Five items similar to each other that were not attitude item were removed from the scale. After the corrections made, the item pool was reduced to 53 items. The items created are of the five-point likert type and evaluted as I certainly do not agree (1), I do not agree (2), indecisive (3), I agree (4), I strongly agree (5). Pilot scheme was conducted with a total of 305 higher education administrators and academicians working at Ankara, Gazi, Başkent, and Hacettepe universities in spring semester 2016-2017. The KMO value of the scale was found to be 0,696 . As a result of the factor analysis, it was determined that the 25 scale items were collected in 3 factors and the total variance of scale was $78.587 \% .25$ items with an item load higher than .40 were included to the scale. Loads of the items in the final scale consisting of 3 factors and 25 items are between .42 and .80. The Cronbach Alpha coefficient of the final scale was calculated as 0.87 and found to be highly reliable. The results of item analysis based on averages of the upper and lower groups of all the items in the scale were found to be significantly distinctive ( $p$ $<.05)$. It is thought that this research will contribute to higher education administrators and academicians and researches to be done in the field of crisis and chaos management.
\end{abstract}

Keywords: crisis and chaos management, attitude, scale development

\section{INTRODUCTION}

In recent years, crisis and chaos management, a concept that we often hear about in management science, presents a new look to the concept of management (Aydemir and Demirci, 2005). The inevitable aspect of our time, rapid change, competition and the ability of the organizations to survive in the physical environment they are in are closely related to their being prepared for crisis situations. Previous planning and preparations in the face of unforeseen circumstances vary depending on the nature of the management's decisions in response to adverse situations that may arise in possible crisis situations (Augustine, 2000).

The perception of crisis and chaos signals is directly proportional to the manager's professional competence, personal characteristics and the power to predict the future. Institutional managers are able to identify the possible crisis signals in the future and provide the necessary transformation for their institutions when they sensitively monitor the expectations of the individuals and the circles in the institution and the changes taking place there (Sayın, 2008). The information flow between institutions' information retrieval systems is effective in crisis management. However, not taking into account the signals that might come from the employees and the surrounding people makes it more difficult to get rid of the crisis environment. 


\section{Contribution of this paper to the literature}

- Crisis management is a complex and volatile process that cannot be reduced to a single formula therefore this study advices effective and strong management to cope with the crisis situations in schools.

- In this study, attitude scale towards Higher Education Administrators' Crisis and Chaos Management was developed.

- It is necessary to increase the sensitivity and management skills of institution managers of institutions against possible crises.

The main characteristics of crisis and chaos processes in institutions are the difficulties of unpredictable, urgent intervention, the threats to the purpose and existence of organizations, and the situations where prevention mechanisms of organizations are inadequate. What you need to do to overcome these processes is to make a longterm, intensive and planned work. Managers who are sensitive to the needs, desires and expectations of employees, who can motivate, reassure, remove worries and concerns in these troubled processes created by change, play a crucial role in overcoming crisis situations (Can, 2007). The continuity of an institution depends on how the crisis is managed and how the crisis is managed depends on the managers of the institution. Crises are so difficult periods which managers cannot solve by just using their experiences and communication skills. Effective measures against crime must be systematically studied in order to minimize damage from existing danger and threats. In this context, crisis management refers to measures that organizations should take against possible crises. Crisis management, which can be defined as obtaining the signs of crisis, evaluation, taking necessary precautions to ensure that the organization can survive the crisis with minimum loss, determination and implementation of strategies that can be used constitutes an important aspect of contemporary management approach with this feature (Demirtas, 2000). The effects and negative consequences of crises emerging in this context are inversely proportional to the way they are managed (Erten, 2011). As a result of the inefficiency of the administration in managing crises, the crisis in an organization leaks into other organizations, such as intervening rings, and ultimately creates an environment of chaos. Crisis management is a complex and volatile process that cannot be reduced to a single formula. Thus, dealing with the crisis requires effective and strong management.

In the field literature, it is pointed out that the most effective element in the crisis and chaos management process is the top managers of the institutions and managers are needed mostly during times of crisis (Sayın, 2008). Because the managerial skills to be shown by the administrators rescue the institutions from being dispersed and help the crisis situation to be eliminated as soon as possible by eliminating the panic created by the crisis. Crisis times are the times when managers are most needed. In this process, special and superior skills are expected from the managers of the company for effective crisis and chaos management. There are many factors that can cause crisis in terms of higher education organizations. In crisis situations management, which is defined as the production of goods and services as a result of organizing the material and human resources in the most appropriate way, consists of a number of processes. The operating way of these processes directly affect the structure of the organization, its efficiency, its effectiveness in producing goods or services. At the same time, the phenomenon of management that gives life to organizations is also influenced by changes in the organizational structure (Duff, 2007). Institutions can be influenced by factors of their own internal structures, and by external factors as well. From this point, situations that deviate from normal conditions that can deeply affect organizations are generally defined as crisis situations. The ability to overcome this extraordinary situation, which affects organizational management, necessitates the implementation of crisis management principles. For this reason, it is important to determine the opinions of the managers and academic staff in higher education on the topic of crisis management, and to propose suggestions that can contribute to solving the problem in this direction (Aydemir \& Demirci, 2005).

In higher education, which is an educational organization, crisis and chaos can be experienced as a result of unusual unexpected situations. Preventing crises in higher education institutions and ensuring security is one of the most important problems in recent years, especially for developed societies (Sayin, 2008). It is necessary to increase the sensitivity and management skill of institution managers for the possible crises to be experienced in the institutions. However, at this stage, the lack of sufficient knowledge, skills and know-how on what to do before, during and after the crises of the administrators is an important problem (Sahin, 2006).

In the researches on higher education related to crisis and chaos management, there are no measuring tools that can be used to reveal the thoughts of the administrators and academics about crisis management in the sources available in Turkey, to evaluate the situation of managers' ability in crisis and chaos management and how they cope better with crises. In this direction, the need to develop the scale in order to reveal the attitudes of higher education administrators and academics towards crisis and chaos management was generated. 


\section{METHOD}

\section{Research Model \& The Study Group}

This study was conducted in the general screening model. The screening method aimed at achieving wide participation in attitude development studies can be applied. In this context, scale data were gathered from a total of 305 teaching staff in the Ankara, Gazi, Başkent, Hacettepe university of Ankara province during the spring semester of 2016-2017, who continue to serve as academicians in higher education at the university. In order to perform factor analysis, the number of samples is accepted as 200 medium, 300 good and 500 very good (Devellis, 2014; Tavşanc1l, 2006). The number of people in the study group is well suited to the size of the sample to ensure that factor analysis can be performed.

\section{Development Steps of the Measurement Tool}

In this research, it was aimed to develop attitude scale of Higher Education Administrators towards Crisis and Chaos Management. In this context, firstly, the literature search for the Crisis and Chaos Administration was conducted. Expert opinions were obtained after the field literature was scanned. After the opinions of the experts, 10-question feedback form was prepared. Information was gathered to determine the status of the Crisis and Chaos Management of 10 Higher Education Managers who were continuing their administration in a higher education. Expert opinions and data collected from the students were analyzed and a measurement tool of 58 items was created.

The 58-item scale prepared was presented to 3 field experts and 1 language expert to determine the content validity and language understandability. In line with the responses of the experts, five items were removed from the scale and a 53 -item scale was created. 50 of the scale items have positive and 3 have negative expressions. The items created are of the five-point likert type and evaluted as I do not totally agree (1), I do not agree (2), indecisive (3), I agree (4), I totally agree (5).

53-point pilot application of the Crisis and Chaos Management Attitude Scale of Higher Education Administrators was carried out with 13 higher school administrators. After the pilot application, the two items that were thought to be not understood by the managers were corrected and the scale was again made ready for the actual application as 53 items.

The validity of the constructs has been examined in order to determine to what extent the specified properties of the questions in the scales are measured correctly. An exploratory factor analysis was performed to determine the construct validity of the scale. Exploratory factor analysis is defined as a technique that is designed to examine the covariance structure of a group of variables and to explain the relationships among these variables with respect to the fewer hidden obscure variables called factors. It has a computational power that is based on the relationship between the observed variables, aiming to reach a small number of explanatory factors (grasp) that explain the maximum variance (Büyüköztürk, 2011).

\section{Data Analysis}

After the Higher Education Managers' Crisis and Chaos Management Attitude Scale was applied to the research group, statistical analyzes were conducted to reveal the psychometric properties of the scale. First, validity of the scale was examined. For this purpose, Exploratory Factor Analysis (AFA) and Confirmatory Factor Analysis (DFA) were applied. The reliability of The Crisis and Chaos Management Attitude Scale of Higher Education Managers was examined by Cronbach alpha analysis.

\section{FINDINGS}

\section{Validity of the Study}

In this study Exploratory Factor Analysis and Confirmatory Factor Analysis were carried out in order to examine the construct validity of The Crisis and Chaos Management Attitude Scale of Higher Education Managers.

\section{Findings Related to Exploratory Factor Analysis}

Factor analysis was carried out in order to ensure the structural validity of the attitude scale for the Crisis and Chaos Management Attitude Scale of Higher Education Administrators and to obtain a functional dimensioning by determining the factor loads of the items in the scale (Büyüköztürk, 2011). Suitability of the data to factor analysis before factor analysis was tested by Kaiser Meyer Olkin (KMO) and Bartlett test. For the scale consisting of 53 items, 
Table 1. Factor analysis results of the scale

\begin{tabular}{cccc}
\hline Factors & Factor Eigen Values & Explained Variance $\%$ & Cumulative Variance \% \\
\hline 1 & 15,416 & 29,087 & 29,087 \\
\hline 2 & 6,890 & 13,000 & 42,087 \\
\hline 3 & 6,228 & 11,751 & 53,838 \\
\hline 4 & 4,093 & 7,722 & 61,560 \\
\hline 5 & 3,564 & 6,724 & 68,284 \\
\hline 6 & 3,498 & 6,599 & 74,883 \\
\hline 7 & 2,474 & 4,667 & 79,551 \\
\hline 8 & 2,306 & 4,351 & 83,902 \\
\hline 9 & 1,714 & 3,234 & 87,135 \\
\hline 10 & 1,513 & 2,854 & 89,989 \\
\hline 11 & 1,215 & 2,293 & 92,282
\end{tabular}

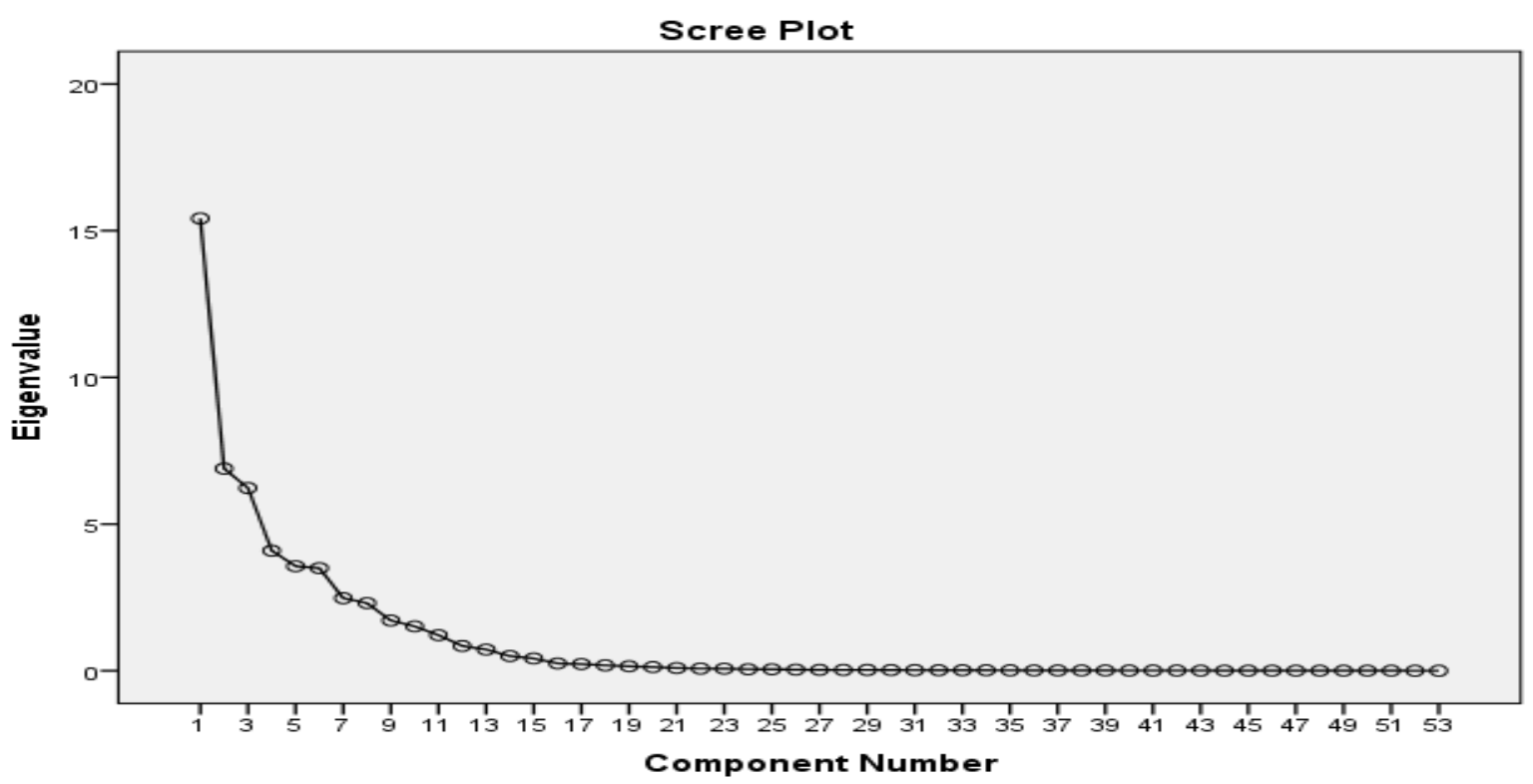

Figure 1. Scree Plot of Exploratory Factor Analysis

the KMO value was 0.966, and the Bartlett test result was $\chi^{2}=3245,704(\mathrm{p} \leq 0.05)$. KMO higher than .60 and a significant result of Barlett test indicates that the data are suitable for factor analysis (Büyüköztürk, 2011). Factor eigen values of the scale items as a result of factor analyzes were calculated (Table 1).

According to the data obtained from the factor analysis, 11 factors above the score of 1.00 describe $92.282 \%$ of the variance in scale scores. Scree plot was examined to determine how many factors the scale will have (Figure 1).

Scree Plot is used to decide on the factor number. Vertical axis shows the eigen values and horizontal axis shows the factors. Points with steep slope in the graph are taken. Points with superficial flat slope are not taken. A horizontal line is drawn from the point where the graph is going horizontal. The point between the points on this line is considered as the size. The factor of high acceleration and rapid decline in the graph gives the number of important factors (Can, 2014). After examining the scree plot in Figure 1, it is decided for the scale to be 3-factorial. Because in social sciences the total variance is expected to be between $40 \%$ and $60 \%$ of the scales (Can, 2014). In order to be suitable for the purpose of studying in this context, it was decided that the scale should be in a three factor structure because the factor structure was considered to be three factors by the researcher. According to the second factor analysis conducted after the factor number was determined, 4, 5, 6, 12, 13, 17, 25, 28, 29, 32, 31, 44, 47, 48 and 52 items with factor load value lower than 0.40 , and 1016 th, 39th and 53rd items with a difference of less than $.10 \mathrm{in} \mathrm{two} \mathrm{factors} \mathrm{were} \mathrm{removed} \mathrm{from} \mathrm{the} \mathrm{scale.} \mathrm{In} \mathrm{the} \mathrm{field} \mathrm{literature,} \mathrm{factor} \mathrm{load} \mathrm{of} \mathrm{an} \mathrm{item} \mathrm{to} \mathrm{be} 0.40$ or more is a good measure for choice. It should also be noted that when a material has a high load value for two factors, the difference between the load values must be at least .10 (Can, 2014). After these items that do no meet the defined values removed, a third factor analysis was made. As a result of the factor analysis for the third time, 2, 18, 22, 27, 36 and 49th items with the factor load value lower than $0.40,3,7,8,20$ and 33 items with a difference of less than .10 in two factors were removed from the scale. 
Table 2. Variance values of factor analysis results

\begin{tabular}{cccc}
\hline Factors & Factor Eigen Values & Explained Variance $\%$ & Cumulative Variance \% \\
\hline 1 & 12,621 & 43,522 & 43,522 \\
\hline 2 & 5,532 & 19,075 & 62,596 \\
\hline 3 & 4,637 & 15,991 & 78,587 \\
\hline
\end{tabular}

Table 3. Factor load values

\begin{tabular}{|c|c|c|c|}
\hline Items & Factor 1 & Factor 2 & Factor 3 \\
\hline M1 &, 802 & & \\
\hline M3 & ,702 & & \\
\hline M9 &, 688 & & \\
\hline M10 &, 683 & & \\
\hline M11 &, 660 & & \\
\hline M14 &, 601 & & \\
\hline M15 &, 598 & & \\
\hline M19 &, 585 & & \\
\hline M21 & & ,705 & \\
\hline M23 & & ,702 & \\
\hline M24 & &, 689 & \\
\hline M26 & & 673 & \\
\hline M30 & &, 659 & \\
\hline M34 & &, 644 & \\
\hline M35 & & ,616 & \\
\hline M37 & &, 579 & \\
\hline M38 & & & ,793 \\
\hline M40 & & & ,743 \\
\hline M41 & & & ,707 \\
\hline M42 & & &, 545 \\
\hline M43 & & &, 542 \\
\hline M45 & & &, 507 \\
\hline M46 & & &, 478 \\
\hline M50 & & &, 467 \\
\hline M51 & & &, 425 \\
\hline
\end{tabular}

Table 4. Factor names

\begin{tabular}{ccc}
\hline Factor $\mathbf{1}$ & Factor $\mathbf{2}$ & Factor $\mathbf{3}$ \\
\hline Before Crisis and Chaos & Crisis and Chaos Period & After Crisis and Chaos \\
\hline
\end{tabular}

As a result of the factor analysis, the KMO value for the 25-item scale was found to be 0.850 , and the Bartlett test result was found to be $\chi^{2}=24775,960(p \leq 0.05)$. These values show that the scale data are suitable for factor analysis. Factor eigen values of the scale items as a result of factor analyzes were calculated (Table 1).

According to the results of the analysis, the first factor accounts for $43.52 \%$ of the scale, the second factor accounts for $19,075 \%$ and the third factor for $15,991 \%$. It was determined that the scale factors explained $78.587 \%$ of the total variance. In Table 3, under which factor the factor items are collected and factor load values were given.

When Table 3 is examined, it is seen that the item total correlations of all items are higher than 0.40. It was determined that the factor loads of the items change between .42 and .80 . With the remaining items of the scale, a student can score at least 25 and a maximum of 125 points.

\section{Denomination of the Factors}

As a result of the factor analysis, the scale items come together to measure the common feature. Factors were named in this context by taking the opinions of the field experts and examining the studies in the field by taking into account the characteristics of the items that came together for the Crisis and Chaos Management Attitude Scale of the Higher Education Administrators (Table 4). 


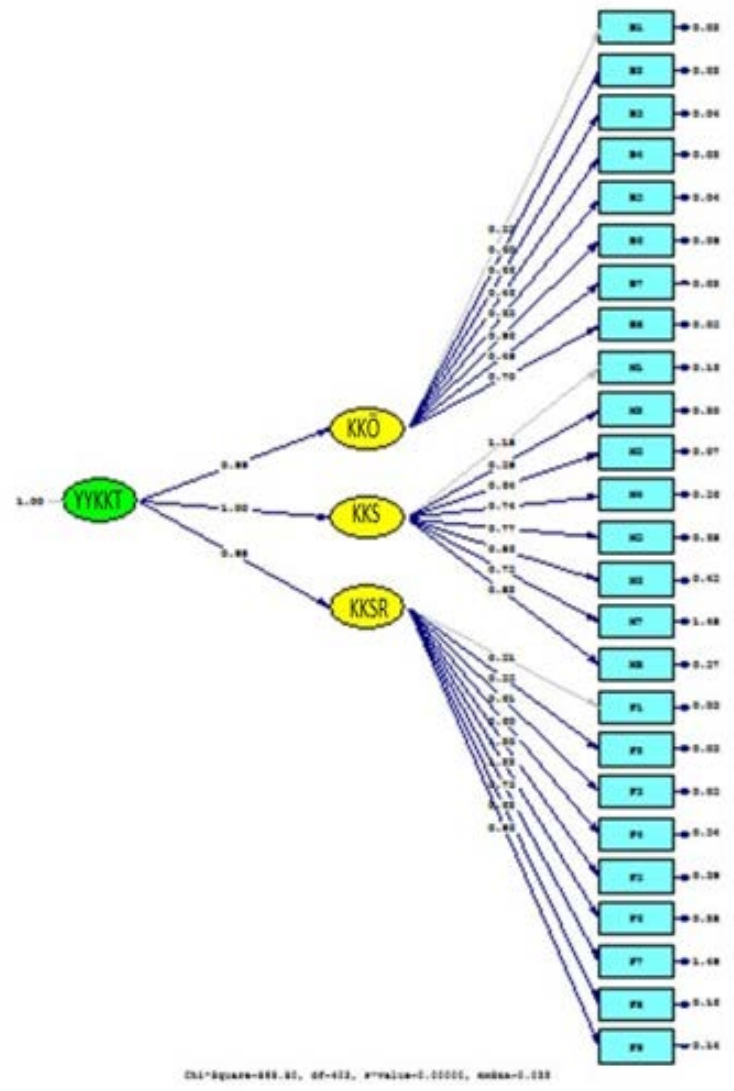

Figure 2. Confirmatory Factor Analysis Results

Table 5. Findings of confirmatory factor analysis

\begin{tabular}{ccccc}
\hline Index & Perfect Consistence Criteria & Acceptable Consistence Criteria & Research Finding & Result \\
\hline$\chi^{2} / s d$ & $0-3$ & $3-5$ & 3,919 & Good Consistence \\
\hline $\mathrm{RMSEA}$ & $.0 \leq \mathrm{RMSEA} \leq .05$ & $.5 \leq \mathrm{RMSEA} \leq 10$ & .099 & Good Consistence \\
\hline $\mathrm{CFI}$ & $.95 \leq \mathrm{CFI} \leq 1.00$ & $.90 \leq \mathrm{CFI} \leq .95$ & .93 & Good Consistence \\
\hline $\mathrm{NNFI}$ & $.95 \leq \mathrm{NNFI}(\mathrm{TLI}) \leq 1.00$ & $.90 \leq \mathrm{NNFI}(\mathrm{TLI}) \leq .95$ & .91 & Perfect Consistence \\
\hline $\mathrm{NFI}$ & $.95 \leq \mathrm{NFI} \leq 1.00$ & $.90 \leq \mathrm{NFI} \leq .95$ & .91 & Perfect Consistence \\
\hline $\mathrm{SRMR}$ & $.0 \leq \mathrm{SRMR} \leq .05$ & $.5 \leq \mathrm{SRMR} \leq .08$ & .06 & Good Consistence \\
\hline $\mathrm{GFI}$ & $.95 \leq \mathrm{GFI} \leq 1.00$ & $.90 \leq \mathrm{GFI} \leq .95$ & .92 & Good Consistence \\
\hline $\mathrm{AGFI}$ & $.90 \leq \mathrm{AGFI} \leq 1.00$ & $.85 \leq \mathrm{AGFI} \leq .90$ & .9 & Good Consistence \\
\hline
\end{tabular}

Source: Schumacker and Lomax, 1996

\section{Confirmatory Factor Analysis Results}

The significance value $\mathrm{p}$ gives information about the significance level of difference (value) between the expected covariance matrix and the observed covariance matrix. P value is expected to be meaningful in DFA (Cokluk, Sekercioğlu \& Büyüköztürk, 2010). $p=.000 ; p<.05$ The difference between the expected covariance matrix and the observed covariance matrix is significant. The consistence indices for the model are given in Table 1.

In DFA, the consistence index that should be examined first is the Chi-square (X2) compliance statistic and if the ratio of degrees of freedom is below 3 , it is perfect consistence and if the it is under 5 , it is good consistence (Kline, 2005). This rate was found to be 3,919. The model shows good consistence.

RMSEA is the square root of the average of error squares. In order for the model to be significant, if it is less than 0.05 , it is perfect consistence, and if it is less than 0.10, it is good consistence (Steiger, 1990). The RMSEA value was found to be 0.099 and shows good consistence.

CFI is a consistence index that compares the covariance matrix estimated by the model with the covariance matrix of the null hypothesis model (Hooper, Coughlan \& Mullen, 2008). CFI takes values between 0 and 1 . It can 
Table 6. Cronbach Alpha reliability analysis results of the scale

\begin{tabular}{ccc}
\hline Factor & Number Of Items & Cronbach's Alfa( $\boldsymbol{\alpha})$ \\
\hline Before Crisis and Chaos & 8 & 0,87 \\
\hline Crisis and Chaos Period & 8 & 0,84 \\
\hline After Crisis and Chaos & 9 & 0,81 \\
\hline Total & 25 & 0,87 \\
\hline
\end{tabular}

be said that a model with a CFI value of 0.95 to 1 is in good consistence, and a model with a CFI value of 0.90 to 0.95 is acceptable (Hu \& Bentler, 1999). The CFI value found in the study is 0.93 , indicating good consistence. The CFI index is the most commonly used consistence index in today's structural equation models (Fan, Thompson \& Wang, 1999).

NFI is the normative consistence index and was developed by Bentler \& Bonett (1980) as an alternative to CFI. This index searches for the consistency of the default model with the baseline or zero hypothesis. The NFI value is found to be 0.91 , indicating perfect consistence. In addition, the NNFI score, which is the non-normative consistence index, is found to be 0.91, indicating that it is perfect (Şehribanoğlu, 2005).

The GFI shows the general amount of covariance between the observed variables calculated in the default model. The GFI value ranges from 0 to 1 . A GFI of 0.90 is considered as a good model indicator. This means that enough covariance was calculated among the observed variables (Schumacker \& Lomax, 1996). The GFI value was obtained as 0.92 , indicating that the model is in good consistence. AGFI is the adjusted consistence index. This value is 0.90 and it shows good consistence.

SRMR is the square root of standardized mean errors. The closer the SRMR value is to 0 , the better the fit of the model. If the model received a SRMR value lower than 0.05 , it is in good consistence, and if it has a SRMR value between 0.05 and 0.08 , it is in acceptable consistence (Hu \& Bentler, 1999). A value of 0.06 found in the study shows good consistent.

\section{Reliability Analysis}

For the reliability analysis of the scale, the Cronbach Alpha coefficient was examined. The Cronbach Alpha reliability coefficient is used when the items are weighted or graded (Can, 2014). In the field literature, it is stated that the values of Cronbach's alpha coefficient between 0.80 and 1 are highly reliable, 0.60 to 0.79 are reliable, 0.40 to 0.60 are less reliable, and 0 to 0.39 are not reliable (Büyüköztürk, 2011). In this context, the Cronbach Alpha coefficients for the scale and its subscales are given in Table 5.

As indicated in Table 5, the Cronbach's alpha coefficient of the scale before crisis and chaos was 0.87, the Cronbach alpha coefficient of crisis and chaos process dimension was 0.84 and the Cronbach alpha coefficient of after crisis and chaos dimension was found to be 0.81 . The Cronbach Alpha coefficient of the complete scale was found to be 0.87 . As a result of the reliability analysis made according to these values, it was determined that the scale sub-dimensions and the complete scale is reliable.

\section{RESULTS}

In this study, it was aimed to develop attitude scale of Higher Education Managers towards Crisis and Chaos Management. The 53-item draft of the scale was applied to 307 higher education administrators and academicians. Substance analysis, internal consistency coefficient and correlation coefficients between the obtained data and the scale, the upper and lower group averages were examined. 25 items with an item load higher than .40 were included to the scale. A three-factor structure was observed for the attitude scale of Higher Education Administrators towards Crisis and Chaos Management developed as a result of exploratory factor analysis. Loads of the items in the final scale consisting of 3 factors and 25 items are between .42 and .80 . DFA was carried out in order to contribute to the structure obtained by AFA. The results obtained show that the resulting structure is acceptable (see Table 5). The Cronbach Alpha reliability coefficient of the final scale was calculated as .870 . Substance analysis results based on averages of the upper and lower groups of all the items in the scale were found to be significantly distinctive ( $p$ $<.05)$.

In the field literature, validity and reliability studies were carried out in order to reveal the attitudes of higher education administrators and academicians to the crisis and chaos management, and the lack of data collection tools were striking. In this direction, the attitude scale of Higher Education Administrators towards Crisis and Chaos Management was developed.

The factors involved in the scale are called before crisis and chaos, crisis and chaos period, and after crisis and chaos. 8 items, which are under the factor of after crisis and chaos, consist of plans and practices to follow and do after the crisis and chaos for higher education administrators and academicians. 8 items, which are under the factor 
of crisis and chaos period, consist of plans and practices to follow and do after the crisis and chaos for higher education administrators and academicians. 9 items, which are under the factor of crisis and chaos period, consist of plans and practices to follow and do after the crisis and chaos for higher education administrators and academicians.

Along with the provision of crisis management in the field literature; it is stated that it will be possible to prevent the dissemination of crisis to different institutions (Ocak, 2007), financial damages to be minimized at the lowest level (Erten, 2011), cooperation (Özdemir, 2002) and the transformation of crisis into opportunity (Savç1, 2008). With the provision of the chaos management, the productivity and yield will increase, and as a result of the collaborative work the institutions will be maintained (Öge, 2005). In this context, it is seen that the internal consistency coefficients of the three factors obtained in accordance with the purpose of working are above .70 and that these factors make consistent measurements within themselves. At the end of this study, attitude scale towards Higher Education Administrators' Crisis and Chaos Management was developed as valid and reliable. As a result of the developed scale, the attitudes of Higher Education Administrators towards Crisis and Chaos Management can be determined in the direction of giving and suggestions can be developed for solving the problems encountered. In addition, the data obtained using this attitude scale can be designed to relate to the different variables in the crisis and chaos management process.

\section{REFERENCES}

Augustine, N. R. (2000). Managing The Crisis You Tried To Prevent. Anthology from Harward Business Review: Crisis Management. (S. Atay, Çev.). İstanbul: Acar Printing (MESS Publishing No: 328).

Aydemir, M., \& Demirci M. K. (2005). An analysis of the positive effects of recent crises on businesses. Cumhuriyet University Social Sciences Journal, 29(1), 65-81.

Büyüköztürk, S. (2011). Data Analysis Handbook for Social Sciences. Ankara: PegemA Publishing.

Can, A. (2014). Quantitative Data Analysis in the Scientific Research Process with SPSS. Ankara: PegemA Publishing.

Can, H. (1997). Organization and Management. Ankara: Siyasal, 312.

Çokluk, Ö., Şekercioğlu, G., \& Büyüköztürk, Ş. (2010). Multivariate Statistics for Social Sciences SPSS and LISREL Applications (1st Print). Ankara: PegemA Akademi Publishing House.

Demirtas, H. (2000). Crisis management. Education Management in Theory and Practice. 23, 353-373.

Donmez, B. (2001). School security problem and the role of school manager. Education Management in Theory and Practice, 7(25), 63-74.

Duff, E. D. (2007). Evaluation of crisis management and the implementation of employee training for emergency preparedness in a private college (Unpublished Ph.D. Thesis). Nova Southeastern University, Florida, United States.

Erten, S. (2011). Crisis Management Understanding in Turkish Public Administration (Unpublished Ph.D. Thesis). Isparta: Suleyman Demirel University.

Fan, X., Thompson, B., \& Wang, L. (1999). Effects of sample size, estimation methods, and model specification on structural equation modeling fit indexes. Structural Equation Modeling, 6(1), 56-83.

Hooper, D., Coughlan, J., \& Mullen, M. (2008). Structural equation modelling: guidelines for determining model fit. Electronic Journal of Business Research Methods, 6(1), 53-60.

Hu, L. T., \& Bentler, P. M. (1999). Cutoff Criteria for Fit Indexes in Covariance Structure Analysis: Conventional. Structural Equation Modeling: A Multidisciplinary Journal, 6(1), 1-55.

Karaköse, T. (2007). Organizations and crisis management. Social Science E-Journal, 13, 1-15.

Kline, R. B. (2005). Principle and Practice of Structural Equation Modelling (Second Edition). New York: The Guilford Press.

Ocak, Y. (2014). Crisis management in secondary schools (Edirne municipality example) (Unpublished Ph.D. Thesis). Edirne: Trakya University.

Ozdemir, T. A. (2002). Evaluation of the coordination qualifications of the primary school heads in the crisis management (Unpublished Master Thesis). Duzce: Abant İzzet Baysal Univ.

Savc1, S. (2008). Perceptions of teachers working in secondary schools on crisis management (Unpublished Ph.D. Thesis). Denizli: Pamukkale University.

Sayın, N. (2008). Investigation of crisis management strategy in secondary education institutions (Istanbul province example) (Unpublished Ph.D. Thesis). Istanbul: Marmara University.

Schumacker, R. E., \& Lomax, R. G. (1996). A Beginner's Guide to Structural Equation Modeling. Mahwah, New Jersey: Lawrence Erlbaum Associates, Publishers. 
Sehribanoğlu, S. (2005). Structural equation models and an application (Unpublished Ph.D. Thesis). Van: Yüzüncü Yıl University Institute of Science.

Serdar, Ö. G. E. (2005). Order or disorder (chaos)? An assessment of the sustainability of organizational presence. Selcuk University Journal of Social Sciences Institute, (13), 285-303.

Steiger, J. H. (1990). Structural model evaluation and modification. Multivariate Behavioral Research, 25, 214-12.

http://www.ejmste.com 